\title{
Assessment of Arias Intensity of historical earthquakes using modified Mercalli intensities and artificial neural networks
}

\author{
G-A. Tselentis \\ University of Patras, Seismological Lab, RIO 265 04, Greece
}

Received: 21 May 2011 - Revised: 14 September 2011 - Accepted: 15 September 2011 - Published: 2 December 2011

\begin{abstract}
This paper presents the development of a nonparametric forecast model based on artificial neural networks for the direct assessment of Arias Intensity corresponding to a historic earthquake using seismic intensity data. The neural models allow complex and nonlinear behaviour to be tracked. Application of this methodology on earthquakes with known instrumental data from Greece, showed that the artificial neural network forecast model have excellent data synthesis capability.
\end{abstract}

\section{Introduction}

With widespread use of strong motion recorders, it is possible to obtain engineering seismic parameters (ESP), such as Arias Intensity $\left(I_{\mathrm{a}}\right)$ for the majority of strong earthquakes that occur today. Many investigators have compared these parameters to seismic intensity data, but have found that the correlation is usually poor and the relationships are highly nonlinear in nature (e.g., Tselentis and Vladutu, 2010).

Since most loss-estimation methodologies (seismic scenarios) in use today (Kaestli et al., 2006), are based on the distribution of ESP, the task of forecasting these parameters from seismic intensity is very important to quantify the effect of historical earthquakes for which no instrumental data are available. In the present investigation by seismic intensity, we refer to the Modified Mercalli Intensity scale (MMI).

Arias Intensity, as defined by Arias (1970), is the total energy per unit weight stored by a set of undamped simple oscillators at the end of an earthquake. The Arias Intensity for ground motion in the $X$ (i.e., $\mathrm{E}-\mathrm{W}$ ) direction is calculated as follows

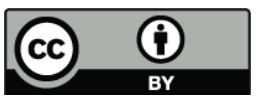

Correspondence to: G-A. Tselentis (tselenti@geology.upatras.gr)
$I_{\mathrm{a} X}=\frac{2 \pi}{g} \int_{0}^{t_{0}} a_{X}^{2}(t) \mathrm{d} t$

where $a_{X}(t)$ is the corresponding acceleration time history and $t_{0}$ is the total duration of the ground motion. In the present investigation by $I_{\mathrm{a}}$, we mean the sum of the two horizontal components $I_{\mathrm{a}}=I \mathrm{a}_{\mathrm{EW}}+I \mathrm{a}_{\mathrm{NS}}$.

We attempt to use a flexible class of statistical models to investigate the relationship of parameters derived from seismic intensity to $I_{\mathrm{a}}$, which essentially becomes a patternmatching problem and is implemented by the use of artificial neural networks (ANN). The significant advantage of the ANN approach in estimating $I_{\mathrm{a}}$ from seismic intensity data is that one does not need to have a well-defined process for algorithmically converting an input to an output. All we need is a set of representative examples of the desired mapping then the ANN automatically adapts itself to reproduce the desired output when presented with a training sample input.

\section{MMI intensity relations}

There are many ESP to MMI estimation equations proposed by various researchers. A significant limitation of these equations is that most of them consider only ground motion to intensity estimation, with intensity the depended value in the regression. Thus, one should only use these equations for assessing the MMI, given a ground motion and not to assess ESP from intensity data.

Despite the doubtful conceptual validity of the MMI-ESP correlations, this approach offers the possibility of transforming quantitative, readily observed data (intensity) into parameters which are useful for engineering purposes (such as $I_{\mathrm{a}}$ ) and is widely used to evaluate the historical earthquakes for which no instrumental data are available.

A key task into the development of ShakeMaps (Wald et al., 1999a) is the construction of regional specific relationships between ESP and MMI. During the last decades, many

Published by Copernicus Publications on behalf of the European Geosciences Union. 
attempts were made to develop region specific ESP-intensity relationships (Ambraseys, 1974; Atkinson and Kaka, 2007; Atkinson and Sonley, 2000; Cabanas et al., 1997; Kaka and Atkinson, 2004; Kaliopoulos et al., 1998; Margottini et al., 1992; Murphy and O’Brien, 1977; Panza et al., 1997; Schenk et al., 1990; Trifunac and Brady, 1975; Wald et al., 1999b; Wu et al., 2003). These studies are region specific, and the proposed ESP-intensity relationships are suitable to that particular seismotectonic and building characteristics of the regions.

Allen and Wald (2009) evaluated the performance of several modern ESP-MMI equations (Wald et al., 1999; Atkinson and Kaka, 2007; Tselentis and Danciu, 2008) and found that these relations specify a standard deviation of the order of one MMI unit. Since the successful application of Shake maps in seismic risk assessment (Wald et al., 1999a), various investigators have addressed the problem of assessing intensities from ESP. This conversion is usually necessary with historical earthquake studies, where intensity data are available and is of interest to assess ESP.

Although it is common practice to simply invert ESP-MMI relations to get an ESP, it is not necessarily correct (Wald et al., 1999a). An exception is the relationship proposed by Faenza and Michelini (2010), since it is based on an orthogonal distance regression and can be applied both ways, i.e., derive PGA from MMI and vice versa.

In Greece, Theodulidis and Papazachos $(1992,1994)$ and Tselentis and Danciu (2008) proposed various empirical relations between MMI and ESP. Koliopoulos et al. (1998), produced an empirical regression equation for MMI and various ground motion parameters. The main goal of the study was to investigate the relationship between duration and energy characteristics of Greek strong ground motion data. Recently, Tselentis and Vladutu (2010) followed a genetic algorithm approach to investigate the relation between MMI and various ESP.

\section{Data}

The database used for this study is derived primarily from readily available strong motion data that have been recorded for felt earthquakes in Greece in the last $40 \mathrm{yr}$ and provided by the European Strong Motion Database (Ambraseys et al., 2004).

The horizontal components of ground motion have been selected, no vertical components were considered and it was decided to treat each horizontal component independently rather than to introduce a vector sum of the two components, because the maximum values of ground motion parameters are not realized simultaneously in each component and, therefore, any computed quantities based on summation would be the upper bounds of the parameters of interest, thus, limiting their practical use (Koliopoulos et al., 1998).

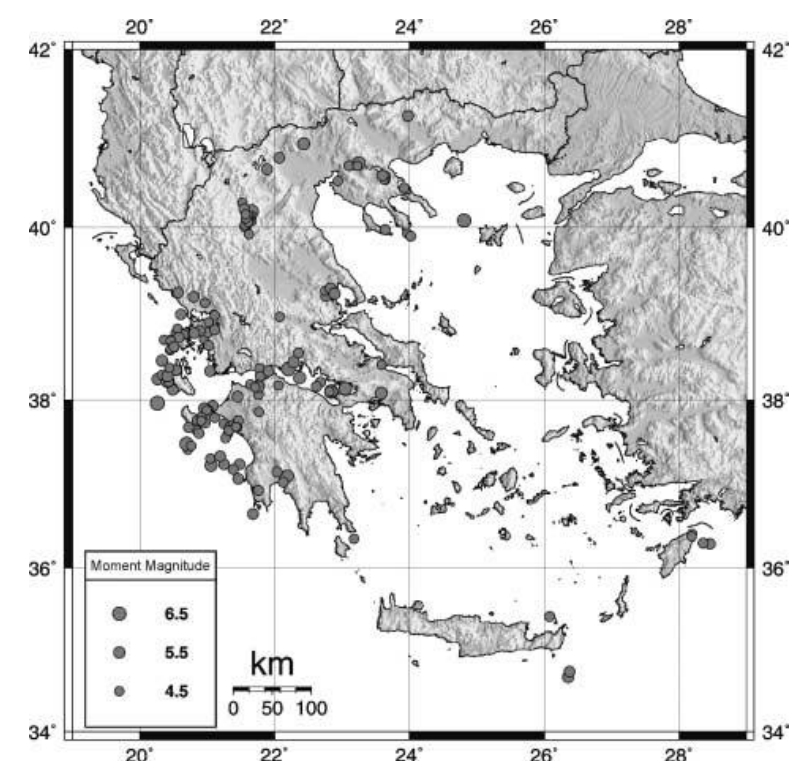

Fig. 1. Epicentral distribution of earthquakes used in the present analysis.

The final dataset consists of 328 time histories recorded from earthquakes which occurred in Greece (Fig. 1). Table 1 provides a list of these earthquakes. No correction has been applied to the selected records because these records were available in an already corrected form. The magnitude scale, which we will refer to as $M$ in this article, corresponds to the moment magnitude (Hanks and Kanamori, 1979).

For the selected dataset based on data from Greece, $M$ is ranging between 4.5 and 6.6.

Since most of the events are offshore and for those onshore the surface geology does not often show any evident faulting, it is impossible to use a fault distance definition like the closest distance to the fault rupture or to the surface projection of the rupture. Thus, we decided to use the epicentral distance. Hypocentral depths of the selected earthquakes are in the interval 0 to $30 \mathrm{~km}$ with a mean of $11.14 \mathrm{~km}$. Most of the intensity information was available through the European Strong Motion Database (Ambraseys et al., 2004) and completed by the macroseismic database developed by Kalogeras et al. (2004). The macroseismic database covers most of the strong earthquakes occurred in Greece and for each event MMI values are assigned to every recording station.

The corresponding, to each earthquake, isoseisms were constructed using the kriging methodology. Kriging is a statistical technique that estimates unknown values at specific points in space using data values from known locations. The main assumption when using kriging is that the data analysed are samples of a regionalized variable, as is assumed to be the case with intensity data. A regionalized variable varies continuously in such a manner that points near each 
Table 1. Database of strong motion records used. $R$ is the epicentral distance, $M_{\mathrm{W}}$ is the body wave magnitude, Soil parameter is 0 for rock $\left(V s>800 \mathrm{~m} \mathrm{~s}^{-1}\right), 1$ for stiff soil $\left(V s=360-665 \mathrm{~m} \mathrm{~s}^{-1}\right)$ and 2 for soft soil $\left(V s=200-360 \mathrm{~m} \mathrm{~s}^{-1}\right)$.

\begin{tabular}{|c|c|c|c|c|c|c|}
\hline Earthquake Name & Date & $R(\mathrm{~km})$ & $M_{\mathrm{W}}$ & soil & MMI & $I_{\mathrm{a}}$ \\
\hline Ionian & $04 / 11 / 1973$ & 15 & 5.8 & 0 & 7 & 0.5021 \\
\hline Ionian & 4/11/1973 & 9 & 4.8 & 0 & 5 & 0.0238 \\
\hline Patras & $29 / 01 / 1974$ & 13 & 4.5 & 0 & 5 & 0.0006 \\
\hline Achaia & $18 / 05 / 1978$ & 8 & 4 & 0 & 5 & 0.0006 \\
\hline Volvi & $20 / 06 / 1978$ & 29 & 6.2 & 0 & 7 & 0.1737 \\
\hline Volvi & $20 / 06 / 1978$ & 29 & 6.2 & 0 & 7 & 0.2071 \\
\hline Alkion & $24 / 02 / 1981$ & 20 & 6.6 & 0 & 7 & 0.8195 \\
\hline Alkion & $24 / 02 / 1981$ & 19 & 6.6 & 0 & 8 & 0.8882 \\
\hline Alkion & $25 / 02 / 1981$ & 25 & 6.3 & 0 & 6 & 0.1826 \\
\hline Preveza & $3 / 10 / 1981$ & 28 & 5.4 & 1 & 7 & 0.2569 \\
\hline Preveza & 3/10/1981 & 42 & 5.4 & 0 & 7 & 0.0483 \\
\hline Kefallinia island & $17 / 01 / 1983$ & 104 & 6.9 & 0 & 6 & 0.1058 \\
\hline Kefallinia island & $17 / 01 / 1983$ & 124 & 6.9 & 1 & 5 & 0.0156 \\
\hline Kefallinia (after & $23 / 03 / 1983$ & 11 & 5.2 & 0 & 5 & 0.0284 \\
\hline Kefallinia (after & $23 / 03 / 1983$ & 72 & 6.2 & 0 & 4 & 0.0118 \\
\hline Elis & $13 / 08 / 1985$ & 18 & 4.9 & 1 & 5 & 0.0132 \\
\hline Near coast of Pre & $31 / 08 / 1985$ & 13 & 5.2 & 1 & 6 & 0.0352 \\
\hline Near coast of Pre & $31 / 08 / 1985$ & 21 & 5.2 & 0 & 6 & 0.0389 \\
\hline Kalamata & $13 / 09 / 1986$ & 11 & 5.9 & 1 & 8 & 0.7413 \\
\hline Kalamata (aftersh & $15 / 09 / 1986$ & 3 & 4.9 & 1 & 7 & 0.2818 \\
\hline Dodecanese & $10 / 5 / 1987$ & 26 & 5.3 & 1 & 5 & 0.0179 \\
\hline Ionian & 24/04/1988 & 13 & 4.8 & 0 & 6 & 0.2044 \\
\hline Etolia & $18 / 05 / 1988$ & 23 & 5.3 & 2 & 7 & 0.1454 \\
\hline Kyllini & $16 / 10 / 1988$ & 36 & 5.9 & 1 & 7 & 0.1416 \\
\hline Kyllini & $16 / 10 / 1988$ & 14 & 5.9 & 1 & 7 & 0.2949 \\
\hline Patras & $22 / 12 / 1988$ & 5 & 4.9 & 1 & 6 & 0.0307 \\
\hline Patras & $22 / 12 / 1988$ & 14 & 4.9 & 0 & 6 & 0.0056 \\
\hline Patras & $31 / 08 / 1989$ & 21 & 4.8 & 0 & 5 & 0.0185 \\
\hline Aigion & $17 / 05 / 1990$ & 20 & 5.30 & 1 & 6 & 0.0284 \\
\hline Plati & $8 / 8 / 1990$ & 36 & 5.10 & 1 & 4 & 0.0033 \\
\hline Mataranga & $30 / 05 / 1992$ & 28 & 5.2 & 1 & 4 & 0.005 \\
\hline Mataranga & $30 / 05 / 1992$ & 34 & 5.2 & 0 & 3 & 0.0093 \\
\hline Tithorea & $18 / 11 / 1992$ & 25 & 5.9 & 1 & 5 & 0.0129 \\
\hline Gulf of Corinth & $2 / 4 / 1993$ & 9 & 5.30 & 0 & 6 & 0.0535 \\
\hline Near coast of Fil & 34092 & 27 & 5.2 & 1 & 5 & 0.0046 \\
\hline Kallithea & $18 / 03 / 1993$ & 41 & 5.8 & 0 & 4 & 0.0057 \\
\hline Pyrgos (foreshock & $26 / 03 / 1993$ & 16 & 4.9 & 1 & 5 & 0.0054 \\
\hline Pyrgos (foreshock & $26 / 03 / 1993$ & 10 & 4.9 & 1 & 5 & 0.0091 \\
\hline Pyrgos & $26 / 03 / 1993$ & 10 & 5.4 & 0 & 7 & 0.3325 \\
\hline Pyrgos & $26 / 03 / 1993$ & 24 & 5.4 & 1 & 6 & 0.0631 \\
\hline Mouzakaiika & $13 / 06 / 1993$ & 48 & 5.3 & 0 & 5 & 0.0657 \\
\hline Patras & $14 / 07 / 1993$ & 30 & 5.6 & 1 & 5 & 0.0196 \\
\hline Patras & $14 / 07 / 1993$ & 54 & 5.6 & 1 & 5 & 0.0037 \\
\hline Patras & $14 / 07 / 1993$ & 37 & 5.6 & 0 & 5 & 0.0096 \\
\hline Patras & $14 / 07 / 1993$ & 27 & 5.6 & 1 & 6 & 0.0214 \\
\hline Patras & $14 / 07 / 1993$ & 10 & 5.6 & 0 & 7 & 0.1789 \\
\hline Gulf of Corinth & 4/11/1993 & 18 & 5.3 & 1 & 4 & 0.004 \\
\hline Gulf of Corinth & 4/11/1993 & 10 & 5.3 & 1 & 5 & 0.0449 \\
\hline Komilion & $25 / 02 / 1994$ & 16 & 5.4 & 0 & 7 & 0.201 \\
\hline Komilion & $25 / 02 / 1994$ & 29 & 5.4 & 1 & 6 & 0.0231 \\
\hline Ionian & $27 / 02 / 1994$ & 27 & 4.8 & 0 & 5 & 0.0176 \\
\hline Ano Liosia & 36350 & 20 & 6 & 0 & 7 & 0.1537 \\
\hline Ano Liosia & 9/7/1999 & 16 & 6 & 1 & 7 & 0.3382 \\
\hline Ano Liosia & $9 / 7 / 1999$ & 17 & 6 & 0 & 7 & 0.0952 \\
\hline Ano Liosia & 36350 & 19 & 6 & 1 & 7 & 0.0902 \\
\hline Ano Liosia & 9/7/1999 & 19 & 6 & 1 & 6 & 0.0434 \\
\hline Ano Liosia & 9/7/1999 & 20 & 6 & 1 & 6 & 0.0522 \\
\hline Ano Liosia & 9/7/1999 & 18 & 6 & 1 & 6 & 0.064 \\
\hline Ano Liosia & 9/7/1999 & 14 & 6 & 1 & 7 & 0.2942 \\
\hline Ano Liosia & 9/7/1999 & 14 & 6 & 1 & 7 & 0.5939 \\
\hline
\end{tabular}


Table 1. Continued.

\begin{tabular}{|c|c|c|c|c|c|c|}
\hline Earthquake Name & Date & $R(\mathrm{~km})$ & $M_{\mathrm{W}}$ & soil & MMI & $I_{\mathrm{a}}$ \\
\hline Astakos & $22 / 01 / 1988$ & 27 & 5.1 & 2 & 5 & 0.0016 \\
\hline Agrinio & $8 / 3 / 1988$ & 6 & 4.9 & 2 & 6 & 0.0136 \\
\hline Etolia & $18 / 05 / 1988$ & 20 & 5.3 & 1 & 6 & 0.0166 \\
\hline Etolia & $22 / 05 / 1988$ & 21 & 5.4 & 1 & 5 & 0.0123 \\
\hline Kefallinia island & 23/06/1992 & 16 & 5 & 1 & 7 & 0.1409 \\
\hline Skydra-Edessa & $18 / 02 / 1986$ & 2 & 5.3 & 1 & 6 & 0.0601 \\
\hline Griva & $21 / 12 / 1990$ & 36 & 6.1 & 1 & 7 & 0.129 \\
\hline Griva & $21 / 12 / 1990$ & 37 & 6.1 & 1 & 6 & 0.0187 \\
\hline Gulf of Corinth & 32206 & 19 & 4.5 & 1 & 5 & 0.0065 \\
\hline Gulf of Corinth & $3 / 4 / 1988$ & 19 & 4.5 & 1 & 5 & 0.0093 \\
\hline Gulf of Corinth & $7 / 5 / 1988$ & 19 & 4.9 & 1 & 5 & 0.018 \\
\hline Tithorea & $18 / 11 / 1992$ & 61 & 5.9 & 1 & 5 & 0.0096 \\
\hline Kranidia & $25 / 10 / 1984$ & 23 & 5.5 & 2 & 6 & 0.0048 \\
\hline Near coast of Fil & $5 / 3 / 1993$ & 54 & 5.2 & 2 & 5 & 0.0079 \\
\hline Gulf of Kiparissi & $7 / 9 / 1985$ & 37 & 5.4 & 2 & 5 & 0.0045 \\
\hline Kalamata (aftersh & $6 / 10 / 1987$ & 17 & 5.3 & 2 & 6 & 0.0161 \\
\hline Peratia & $22 / 05 / 1986$ & 7 & 4.1 & 0 & 3 & 0.0015 \\
\hline Near NW coast of & $27 / 02 / 1987$ & 52 & 5.7 & 0 & 5 & 0.0124 \\
\hline Levkas island & $11 / 10 / 1992$ & 5 & 4.6 & 0 & 5 & 0.0105 \\
\hline Mouzakaiika & $13 / 06 / 1993$ & 48 & 5.3 & 0 & 5 & 0.018 \\
\hline Komilion & $25 / 02 / 1994$ & 15 & 5.4 & 0 & 7 & 0.1405 \\
\hline Ionian & $27 / 02 / 1994$ & 26 & 4.8 & 0 & 5 & 0.0158 \\
\hline Ierissos & $26 / 08 / 1983$ & 15 & 5.1 & 2 & 6 & 0.0643 \\
\hline Paliouri & $4 / 10 / 1994$ & 5 & 5.1 & 1 & 5 & 0.0089 \\
\hline Patras & $15 / 05 / 1989$ & 6 & 4.8 & 1 & 5 & 0.0078 \\
\hline Patras & $31 / 08 / 1989$ & 21 & 4.8 & 1 & 5 & 0.0237 \\
\hline Mataranga & $30 / 05 / 1992$ & 34 & 5.2 & 1 & 5 & 0.0142 \\
\hline Patras & $14 / 07 / 1993$ & 10 & 5.6 & 1 & 7 & 0.1589 \\
\hline Patras (aftershoc & $14 / 07 / 1993$ & 11 & 4.6 & 1 & 4 & 0.0021 \\
\hline Mataranga & $30 / 05 / 1992$ & 33 & 5.2 & 1 & 5 & 0.0137 \\
\hline Patras & $14 / 07 / 1993$ & 9 & 5.6 & 1 & 7 & 0.1601 \\
\hline Kyllini & $16 / 10 / 1988$ & 78 & 5.9 & 1 & 4 & 0.0034 \\
\hline Patras & $22 / 12 / 1988$ & 14 & 4.9 & 1 & 6 & 0.0049 \\
\hline Kyllini & $16 / 10 / 1988$ & 49 & 5.9 & 0 & 6 & 0.0116 \\
\hline Trilofon & 20/10/1988 & 7 & 4.8 & 0 & 5 & 0.0007 \\
\hline Komilion & $25 / 02 / 1994$ & 12 & 5.4 & 1 & 6 & 0.0676 \\
\hline Kyllini (foreshoc & $22 / 09 / 1988$ & 23 & 5.3 & 1 & 5 & 0.0133 \\
\hline Almiros (aftersho & $16 / 07 / 1980$ & 3 & 5 & 1 & 6 & 0.0611 \\
\hline Almiros (aftersho & $8 / 11 / 1980$ & 14 & 5.2 & 1 & 6 & 0.037 \\
\hline Almiros (aftersho & $26 / 09 / 1980$ & 10 & 4.8 & 1 & 5 & 0.021 \\
\hline Kefallinia (after & $23 / 03 / 1983$ & 9 & 6.2 & 1 & 6 & 0.3968 \\
\hline Drama & $11 / 9 / 1985$ & 19 & 5.2 & 1 & 6 & 0.0193 \\
\hline Drama & $11 / 9 / 1985$ & 51 & 5.2 & 2 & 5 & 0.0208 \\
\hline Kalamata (aftersh & $15 / 09 / 1986$ & 12 & 4.9 & 1 & 6 & 0.0187 \\
\hline Kremidia (aftersh & $25 / 10 / 1984$ & 16 & 5 & 2 & 6 & 0.2228 \\
\hline Ierissos & $26 / 08 / 1983$ & 42 & 5.1 & 2 & 5 & 0.0326 \\
\hline Near coast of Pre & $31 / 08 / 1985$ & 13 & 5.2 & 1 & 6 & 0.0258 \\
\hline Kefallinia (after & $23 / 03 / 1983$ & 65 & 6.2 & 1 & 5 & 0.0173 \\
\hline Near SE coast of & $10 / 4 / 1984$ & 17 & 5 & 1 & 5 & 0.0143 \\
\hline Kyllini & $16 / 10 / 1988$ & 16 & 5.9 & 1 & 5 & 0.0053 \\
\hline Kyllini (aftersho & $23 / 10 / 1988$ & 10 & 4.3 & 1 & 5 & 0.0038 \\
\hline Kyllini (aftersho & $31 / 10 / 1988$ & 14 & 4.8 & 1 & 5 & 0.0117 \\
\hline Kyllini (aftersho & 27/11/1988 & 14 & 4.5 & 1 & 4 & 0.0083 \\
\hline Kyllini (aftersho & $22 / 10 / 1988$ & 12 & 4.5 & 1 & 5 & 0.0041 \\
\hline Kyllini (aftersho & $23 / 10 / 1988$ & 7 & 4.4 & 1 & 5 & 0.0078 \\
\hline Kyllini (aftersho & $27 / 11 / 1988$ & 19 & 4.5 & 0 & 4 & 0.0063 \\
\hline Kyllini (aftersho & 20/10/1988 & 16 & 4.2 & 0 & 5 & 0.0067 \\
\hline Kyllini (aftersho & $22 / 10 / 1988$ & 16 & 4.5 & 0 & 5 & 0.0109 \\
\hline Volvi & 20/06/1978 & 78 & 6.2 & 0 & 5 & 0.0054 \\
\hline Kalamata & $13 / 10 / 1997$ & 48 & 6.4 & 2 & 7 & 0.1921 \\
\hline Strofades & 18/11/1997 & 90 & 6.6 & 2 & 6 & 0.0605 \\
\hline Pyrgos & $8 / 11 / 1996$ & 2 & 4.7 & 0 & 6 & 0.0259 \\
\hline Levkas island & 23/04/1996 & 6 & 3.9 & 1 & 5 & 0.0034 \\
\hline
\end{tabular}


Table 1. Continued.

\begin{tabular}{llrcccr}
\hline Earthquake Name & Date & $R(\mathrm{~km})$ & $M_{\mathrm{W}}$ & soil & MMI & $I_{\mathrm{a}}$ \\
\hline Off coast of Magi & 30475 & 76 & 6.6 & 2 & 6 & 0.0264 \\
Kefallinia island & $23 / 01 / 1992$ & 14 & 5.6 & 1 & 7 & 0.1562 \\
Kozani (aftershoc & $14 / 05 / 1995$ & 6 & 4.5 & 1 & 6 & 0.0214 \\
Kozani (aftershoc & $15 / 05 / 1995$ & 9 & 5.2 & 1 & 7 & 0.136 \\
Kozani (aftershoc & $17 / 05 / 1995$ & 16 & 5.3 & 1 & 6 & 0.0712 \\
Kozani & $13 / 05 / 1995$ & 77 & 6.5 & 1 & 6 & 0.0182 \\
Kozani & $13 / 05 / 1995$ & 71 & 6.5 & 2 & 4 & 0.0115 \\
Arnaia & $4 / 05 / 1995$ & 32 & 5.3 & 1 & 5 & 0.0075 \\
Kozani (aftershoc & $19 / 05 / 1995$ & 16 & 5.2 & 1 & 6 & 0.3339 \\
Kozani (aftershoc & $6 / 11 / 1995$ & 3 & 4.8 & 1 & 6 & 0.0677 \\
Kozani & $13 / 05 / 1995$ & 93 & 6.5 & 1 & 4 & 0.0181 \\
Kozani & $13 / 05 / 1995$ & 72 & 6.5 & 1 & 6 & 0.0172 \\
\hline
\end{tabular}

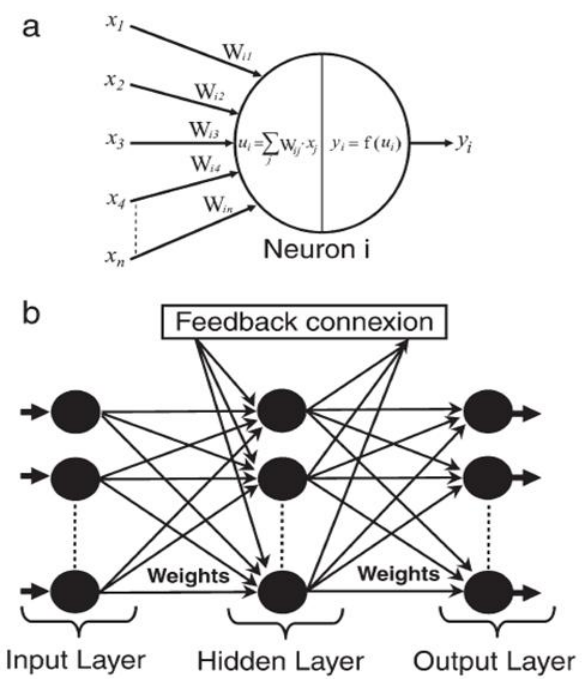

Fig. 2. General topology of a feed-forward ANN with one hidden layer.

other, have a certain degree of spatial correlation, but points that are widely separated are statistically independent.

The kriging estimator applied in the macroseismic dataset considered in the present paper is given by

$I_{j}=\sum_{i=1}^{n} w_{i j} \mathrm{MMI}_{j}$

Where $I_{j}$ is the predicted intensity value at any grid node, $n$ is the number of points used to interpolate at each node, $\mathrm{MMI}_{i}$ is the intensity value at the $i$-th point and $w_{i j}$ is the weight associated with the $i$-th data value when estimating $I_{j}$. The weights are solutions of a system of linear equations which are obtained by assuming that $I$ is a sample-path of a random process and that the error of prediction is minimal.

The kriging algorithm assigns weights to each point based on the distance between the point to be interpolated and the data location $(h)$, as well as the inter-data spacing. Other

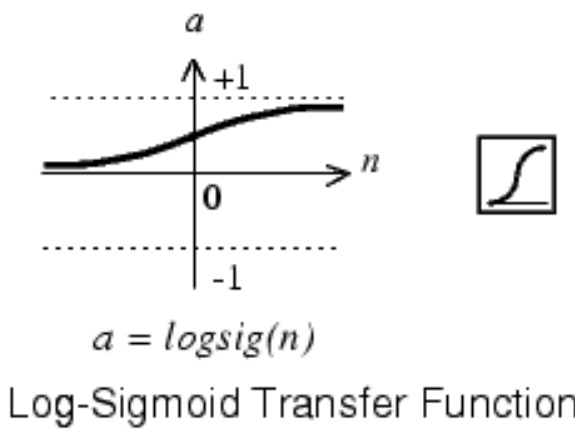

Fig. 3. The nonlinear S-shaped sigmoid activation function used in the present investigation.

parameters, such as length scale, repeatability and direction dependence of data are also considered for assigning weights. These parameters are entred into the algorithm via the variogram $\gamma(h)$, which is an analytical tool that quantifies the degree of spatial autocorrelation of data.

In the present investigation, the isoseismals, that more accurately represented the observed intensity data field, were chosen by modelling a simple linear variogram based on the kriging options of Surfer Package from Golden Software. A detailed explanation of the kriging algorithm and the variogram parameters can be found in De Rubeis et al. (2005).

\section{Artificial neural network}

An artificial neural network is an information processing paradigm that is inspired by the way biological nervous systems, such as the brain, process information. The most basic element of the human brain is a specific type of cell, which provides us with the ability to remember, think and apply previous experiences to our every action. These cells are known as neurons. The power of the brain comes from the number of neurons and the multiple connections (synapses) between them. 
Table 2. Network performance for a different number of neurons in the hidden layer. AIC refers to the Akaike's Information Criterion defined by AIC $=T \ln (\mathrm{RSS})+2 k$, where $k$ is the number of regressors, $T$ the number of observations and RSS the residual sum of square.

\begin{tabular}{lrrrrrr}
\hline ANN & Weights & Train Error & Validation Error & AIC & Correlation & $R$-Squared \\
\hline$[6-1-1]$ & 9 & 0.023 & 0.055554 & -407.1 & 0.831 & 0.659 \\
{$[6-15-1]$} & 121 & 0.026 & 0.051017 & -471.4 & 0.817 & 0.663 \\
{$[6-9-1]$} & 73 & 0.024 & 0.049607 & -575.9 & 0.82 & 0.663 \\
{$[6-5-1]$} & 41 & 0.022 & 0.057709 & -645.3 & 0.84 & 0.708 \\
{$[6-12-1]$} & 97 & 0.028 & 0.050409 & -512.0 & 0.806 & 0.511 \\
{$[6-7-1]$} & 57 & 0.028 & 0.05679 & -592.0 & 0.811 & 0.615 \\
{$[6-10-1]$} & 81 & 0.025 & 0.051625 & -556.3 & 0.807 & 0.613 \\
{$[6-8-1]$} & 65 & 0.0191 & 0.053817 & -608.7 & 0.913 & 0.833 \\
\hline
\end{tabular}

Figure 2 shows a simplified view of a ANN. It consists of a network of simple processing elements (artificial neurons) which are organised in several layers: an input layer (which has the number of neurons linked to the dimensionality of the input), one or several hidden layers and an output layer. The hidden layer provides a representation for the inputs.

When one presents, at the network, a form to be learned, the neurons simultaneously start a state of activity which causes a small modification of the synaptic between the forces. It follows a quantitative reconfiguration of the whole of the synapses, some of them become very strong, the others become weak. The learned form is not directly memorized at a precise place; it corresponds in a particular energy state of the network, a particular configuration of the activity of each neuron, in a very large case of possible configurations. This configuration is supported by the values of the synaptic forces (Haykin, 1999).

Let $Y_{j}^{s}$ represents the output of the $j$-th neuron at layer $s$, $W_{i j}^{s}$ is the weight connecting the $i$-th neuron in layer $s$ to the $j$-th neuron at layer $s-1$. The neurons have their activation function characterised by a nonlinear function (like the Sigmoid function in Fig. 3). This function maps the output to its input and can be expressed by the following equation

$Y_{j}^{s}=f\left(b_{+} \sum_{i=1}^{R} W_{j i}^{s} \times Y_{i}^{s-1}\right)$

where $b$ is the bias.

This relation allows, by knowing the input of the first layer of the network, to gradually calculate the value of the global output of the network, thus, ensuring the forward propagation. When one compares this output with the desired output, one can calculate the error function, generally given by

$e=\frac{1}{2}(Y-\bar{Y})^{2}$

where $Y$ is the desired output and $(\bar{Y})$ the obtained output. The direction in which the weights are updated is given by the negative of the gradient of $\mathbf{e}$ with respect to every element of the weight. This process consists in minimizing $\mathbf{e}$ by a gradient descent. Thus, we try to modify the synaptic

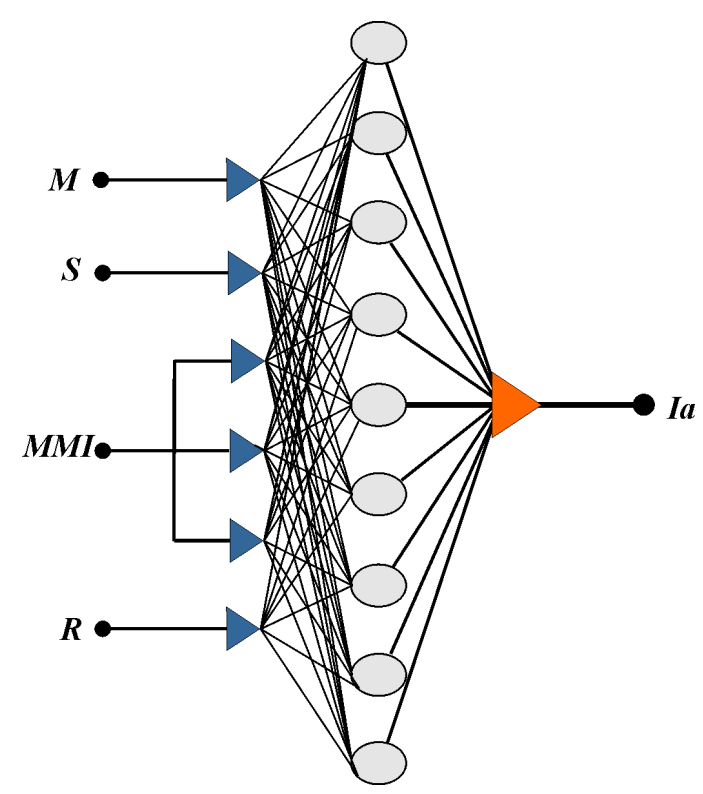

Fig. 4. Topology of the feed-forward $k$-NN-type ANN used in the present study. Input parameters are magnitude $M_{\mathrm{W}}$, Soil parameter $S$, MMI and epicentral distance $R$.

weights in order to reduce e. This is carried out using the following relation

$\Delta w_{i j}^{s}=-\mu\left(e_{j}^{s} Y_{i}^{s-1}\right)_{n}+\left(\Delta w_{j i}^{s}\right)_{n-1}$

where $\mu$ is the learning rate parameter and usually takes values between 0 and 0.5 . The quantity $e_{j}^{s}$ is the local error of the $j$-th neuron in the $s$ layer. Weights and bias terms are first initialized to random values. In general, there are no strict rules to determine the network configuration for optimum training and prediction.

\section{ANN model for seismic intensity}

Data from earthquakes and locations for which both MMI data and Greek strong motion records are available (Table 1) was used to build and train an ANN. Earthquake magnitude, 

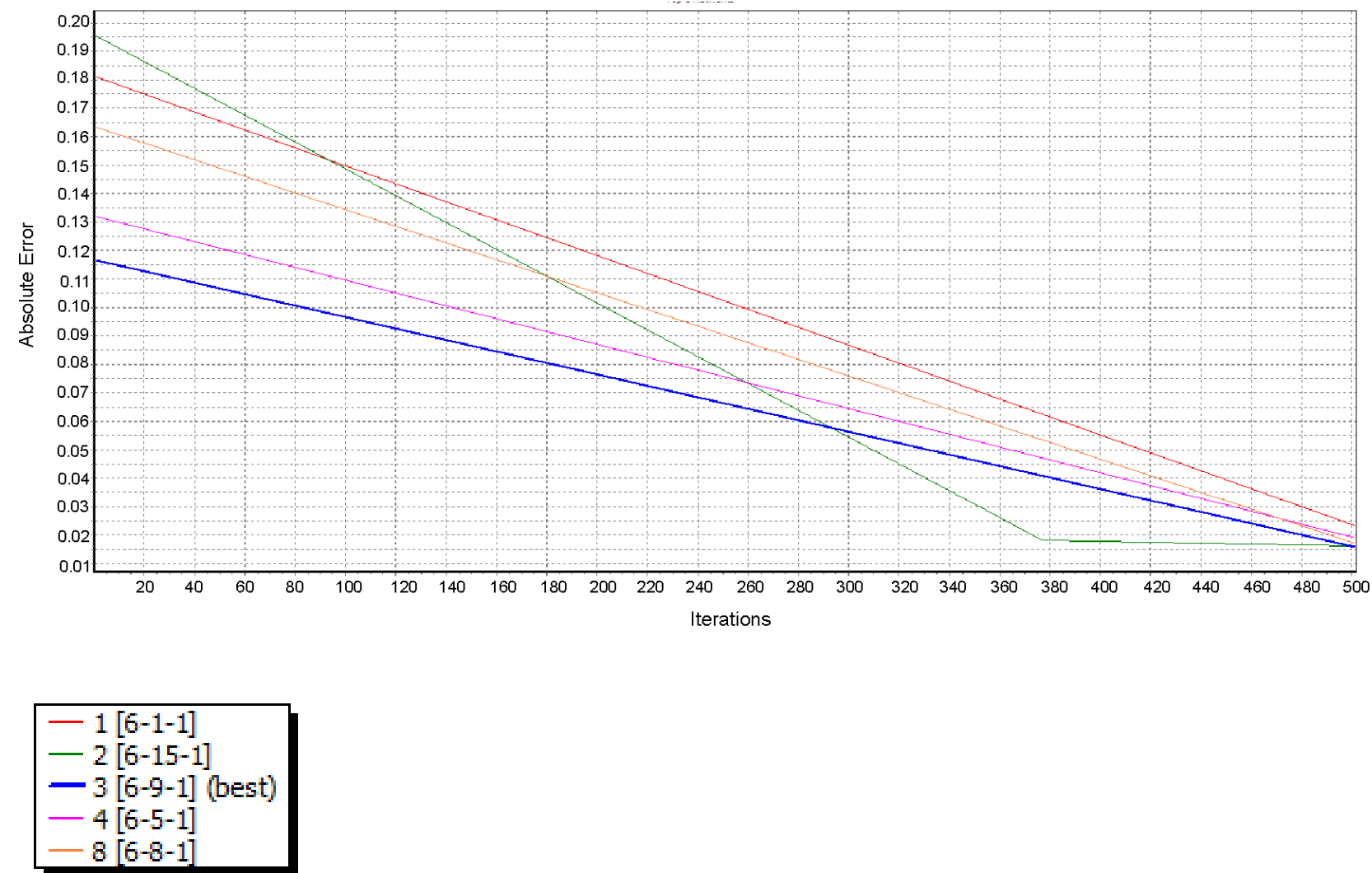

Fig. 5. Absolute ANN error versus No of iterations for different number of neurons in the hidden layer.

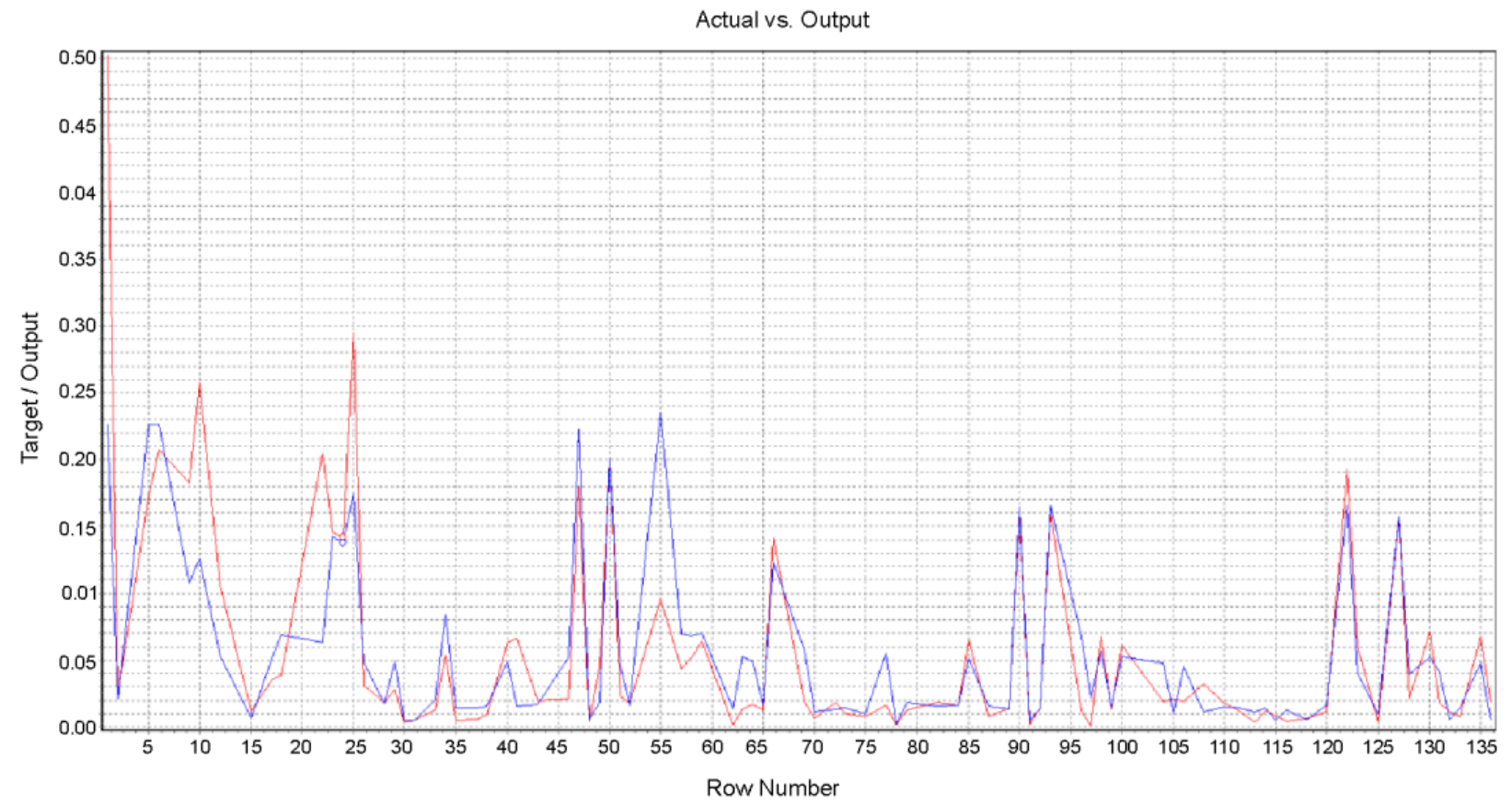

Fig. 6. Comparison of real (red line) and predicted values. 
soil conditions (rock, soil, soft soil), epicentral distance and MMI values were used as input layer variables to a multilayered feed forward ANN. The single output layer variable was the $I_{\mathrm{a}}$ value.

After trying various numbers of hidden layers, we found that the best type of network for the present investigation is that consisting of one hidden layer resulting in a total of three layers (Fig. 4). The Sigmoid function (Fig. 3), was used for the transfer function of the hidden neurons. We changed the number of neurons in the hidden layers and those that gave the smallest error are depicted in Table 2. The performance of the ANN was found to deteriorate as the number of hidden neurons increased farther than the number 15.

For supervised training of the ANN, a subset of two thirds of the total records was used. The individual sites assigned to this training set were selected at random from the complete set of records. The other third of the data was used for testing the ANN after it had been trained.

Figure 5 depicts the ANN absolute error, for various numbers of neurons in the hidden layer, versus the training epoch (iterations). Judging from this figure, we see that the ANN with 9 neurons in the hidden layer has the lowest error and is selected for further data processing.

Finally, a comparison between the results predicted by the ANN and the test data are presented in Fig. 6. The correlation between the predicted and real data is excellent considering the strong nonlinear character of the relation between MMI and $I_{\mathrm{a}}$.

\section{Conclusions}

In the present investigation, we examined the relation between MMI and $I_{\mathrm{a}}$ using a database consisting of Greek earthquakes and employing ANN. It is shown that an ANN can be used to predict $I_{\mathrm{a}}$ from MMI data despite the strong nonlinear nature of the problem. This result is of particular importance in studying historical earthquakes for which there is a big database in Greece.

Acknowledgements. I want to thank M. E. Contadakis for editing the current manuscript and L. Danciu for compiling the Macroseismic data.

Edited by: M. E. Contadakis

Reviewed by: two anonymous referees

\section{References}

Allen, T. I. and Wald, D. J.: Evaluation of ground-motion modelling techniques for use in Global ShakeMap: a critique of instrumental ground-motion prediction equations, peak ground motion to macroseismic intensity conversions, and macroseismic intensity predictions in different tectonic settings, US Geological Survey Open-File Report 2009-1047, Golden, USA, 114 pp., 2009.

Ambraseys, N. N.: The correlation of intensity with ground motions, Advancements in Engineering Seismology in Europe, Trieste, Italy, 12-23, 1974.

Ambraseys, N. N., Smit, P., Douglas, J., Margaris, B., Sigbjörnsson, R., Ólafsson, S., Suhadolc, P., and Costa, G.: Internet site for European strong-motion data, Bull. Geof. Teor. Appl., 45, 113129, 2004.

Arias, A.: A measure of earthquake intensity, in: Seismic Design for Nuclear Power Plants, edited by: Hansen, R. J., MIT Press, Cambridge, Massachusetts, 438-483, 1970.

Atkinson, G. M. and Sonley, E.: Empirical Relationships between Modified Mercalli Intensity and Response Spectra, Bull. Seismol. Soc. Am., 90, 537-544, 2000.

Atkinson, G. M. and Kaka, S. I.: Relationships between Felt Intensity and Instrumental Ground Motion in the Central United States and California, Bull. Seismol. Soc. Am., 97, 497-510, 2007.

Cabanas, L., Benito, B., and Herraiz, M.: An approach to the measurement of the potential structural damage of earthquake ground motions, Earthq. Eng. Struct. Dyn., 26, 79-92, 1997.

De Rubeis,V., Tosi, P., Gasparini, C., and Solipaca, A.:Application of Kriging Technique to Seismic Intensity Data, Bull. Seismol. Soc. Am., 95, 540-548, 2005.

Faenza, L. and Michelini, A.: Regression analysis of MCS intensity and ground motion parameters in Italy and its application in ShakeMap, Geophys. J. Int., 180, 1138-1152, 2010.

Hanks, T. C. and Kanamori, H.: A Moment Magnitude Scale, J. Geophys. Res., 84, 2348-2350, 1979.

Haykin, S.: Neural Networks, MacMillan College Publishing Company, 2nd Edn., 1999.

Kaestli, P. and Faeh, D.: Rapid estimation of macroseismic effects and ShakeMaps using macroseismic data, 1st European Conference on Earthquake Engineering and Seismology, Geneva, Switzerland, 3-8 September 2006, Paper n. 1353, 2006.

Kaka, S. I. and Atkinson, G. M.: Relationships between Instrumental Ground-Motion Parameters and Modified Mercalli Intensity in Eastern North America, Bull. Seismol. Soc. Am., 94, 17281736, 2004.

Kalogeras, I. S., Marketos, G., and Theodoridis, Y.: A tool for collecting, querying and mining macroseismic data, Bull. Geol. Soc. Greece, 36, 1406-1411, 2004.

Koliopoulos, P. K., Margaris, B. N., and Klimis, N. S.: Duration and energy characteristics of Greek strong motion records, J. Earthqu. Eng., 2, 391-417, 1998.

Margottini, C., Molin, D., and Serva, L.: Intensity versus ground motion: A new approach using Italian data, Eng. Geol., 33, 45$58,1992$.

Murphy, J. R. and O'Brien, L. J.: The correlation of peak ground acceleration amplitude with seismic intensity and other physical parameters, Bull. Seismol. Soc. Am., 67, 877-915, 1977.

Panza, G. F., Cazzaro, R., and Vacari, F.: Correlation between macroseismic intensities and seismic ground motion parameters, Ann. Geofis., XL, 1371-1382, 1997. 
Schenk, V., Mantlík, F., Zhizhin, M. N., and Tumarkin, A. G.: Relation between macroseismic intensity and instrumental parameters of strong motions - A statistical approach, Nat. Hazards, 3, 111-124, 1990.

Sørensen, M. B., Stromeyer, D., and Grünthal, G.: Deliverable 4.1: Generation of area-specific relationships between ground motion parameters (PGA, PGV) at certain sites, magnitude $\mathrm{M}$ and distance $\mathrm{R}$ to the causative fault and site intensities in terms of EMS-98, Databank of intensity data points and related parameters, Seismic eArly warning For EuRope, GFZ Potsdam, 19-32, 2007.

Theodulidis, N. P. and Papazachos, B. C.: Dependence of strong ground motion on magnitude-distance, site geology and macroseismic intensity for shallow earthquakes in Greece: I, Peak horizontal acceleration, velocity and displacement, Soil Dym. Earthq. Eng., 11, 387-402, 1992.

Theodulidis, N. P. and Papazachos, B. C.: Dependence of strong ground motion on magnitude-distance, site geology and macroseismic intensity for shallow earthquakes in Greece: II, horizontal pseudovelocity, Soil Dynam. Earthq. Eng., 13, 317-343, 1994.

Trifunac, M. D. and Brady, A. G.: On the correlation of seismic intensity scales with the peaks of recorded strong ground motion, Bull. Seismol. Soc. Am., 65, 139-162, 1975.
Tselentis, G. A. and Danciu, L.: Empirical Relationships between Modified Mercalli Intensity and Engineering Ground-Motion Parameters in Greece, Bull. Seismol. Soc. Am., 98, 1863-1875, 2008.

Tselentis, G-A. and Vladutu, L.: An attempt to model the relationship between MMI attenuation and engineering groundmotion parameters using artificial neural networks and genetic algorithms, Nat. Hazards Earth Syst. Sci., 10, 2527-2537, doi:10.5194/nhess-10-2527-2010, 2010.

Wald, D. J., Quitoriano, V., Heaton, T. H., and Kanamori, H.: Relationships between Peak Ground Acceleration, Peak Ground Velocity, and Modified Mercalli Intensity in California, Earthq. Spectra, 15, 557-564, 1999a.

Wald, D. J., Quitoriano, V., Heaton, T. H., Kanamori, H., Scrivner, C. W., and Worden, C. B.: TriNet "ShakeMaps": Rapid Generation of Peak Ground Motion and Intensity Maps for Earthquakes in Southern California, Earthq. Spectra, 15, 537-555, 1999 b.

Wu, Y.-M., Teng, T.-1., Shin, T.-C., and Hsiao, N.-C.: Relationship between Peak Ground Acceleration, Peak Ground Velocity, and Intensity in Taiwan, Bull. Seism. Soc. Am., 93, 386-396, 2003. 